\title{
Programa nacional de crédito da agricultura familiar e impactos nas economias locais no estado do Paraná
}

\section{National program of family farm credit and impact on local economies in the state of Parana}

\author{
Rodrigo Lopes Antunes ${ }^{1}$ \\ Marcia Regina Gabardo Camara ${ }^{2}$ \\ Sidnei Pereira do Nascimento ${ }^{3}$ \\ Vanderlei José Sereia ${ }^{4}$ \\ João Amilcar Rodrigues Anhesini ${ }^{5}$
}

\section{RESUMO}

O objetivo deste artigo é analisar o impacto do programa nacional de crédito para a agricultura familiar (PRONAF) na economia de 60 municípios paranaenses que contrataram crédito entre 2000 e 2005. A evolução do crédito rural mostra que a partir da década de 1990, há expansão dos contratos e dos recursos; sua intensificação ocorre após 1999, quando introduz a diferenciação entre os agricultores familiares. A agricultura familiar tem grande importância para a economia paranaense, respondendo por $45 \%$ da produção das principais culturas e $65 \%$ dos animais. O estudo é empírico, de natureza econométrica, de corte transversal, tem por finalidade verificar o efeito dos recursos do PRONAF sobre as dimensões sociais, tributária e produtiva do Estado. Conclui-se que há relações estatisticamente significativas entre o PRONAF e as variáveis selecionadas para análise e que após 13 anos de sua institucionalização, continua cumprindo o objetivo de promover o desenvolvimento da agricultura familiar.

Palavras-chave: Agricultura Familiar. Crédito Rural. PRONAF.

\section{ABSTRACT}

The aim of this paper is to analyze the impact of the national credit for family farmers (PRONAF) in savings of 60 municipal districts that hired credit between 2000 and 2005. The development of rural credit shows that from the 1990s, there is an expansion of contracts and resources, intensification occurs after 1999, when he introduces the distinction between family farmers. Family farming has great importance for the state economy, accounting for $45 \%$ of the production of major crops and $65 \%$ of animals. The study is empirical in nature econometric cross-section, is to determine the effect of PRONAF resources on social, tax and productive state. We conclude that there are statistically significant relationships between PRONAF and the variables selected for analysis and that after 13 years of its institutionalization, continues to fulfill the objective of promoting the development of family farming.

Key Words: Family Agriculture. PRONAF. Rural Credit.

\footnotetext{
${ }^{1}$ Economista formado pela Universidade Estadual de Londrina.E-mail: rodrigola@hotmail.com

${ }^{2}$ Doutora em Economia pela FEA-USP. Docente do Departamento de Economia-Universidade Estadual de Londrina. E-mail: mgabardo@,uel.br

${ }^{3}$ Doutor em Economia pela ESALQ-USP. Docente do Departamento de Economia-Universidade Estadual de Londrina. E-mail: sidnei@uel.br

${ }^{4}$ Doutor em Administração pela UNINOVE-USP. Docente do Departamento de Economia-Universidade Estadual de Londrina. E-mail: sereiai@uel.br

${ }^{5}$ Mestre em Economia Regional pela Universidade Estadual de Londrina. E-mail: joaoamilcarr@hotmail.com
} 


\section{INTRODUÇÃO}

O crédito rural procura estimular os investimentos rurais, garantir o valor de custeio da produção, comercialização e consequentemente favorecer o setor rural, o qual é responsável pela produção de alimentos (PLANETA ORGANICO, 2009).

O espaço agrícola brasileiro é formado por uma diversidade de ambientes físicos, espaços, relações sociais, culturas, etnias, sistemas de produção entre outros. Historicamente esta diversidade traduz na convivência lado a lado de duas linhas opostas de agricultura, a patronal que utiliza o modelo de monocultura e latifúndio de commodities agrícolas, gerando exploração do trabalho agrícola, desigualdade e degradação ambiental. Do lado oposto está a agricultura familiar, baseada na produção de alimentos para o próprio consumo ou para a segurança alimentar da população em geral; o modelo baseia-se na valorização do trabalho familiar e contribui para o desenvolvimento sustentável do campo (RELATÓRIO DO PRONAF, 2008).

Devido à crise financeira vivida pelo país nos meados dos anos 80 , a agricultura familiar foi vista como alternativa ao abastecimento de alimentos e como solução para amenização do quadro de miséria e desemprego que assolava o país neste período. Se as pequenas propriedades que utilizam a mão de obra familiar recebessem o devido apoio técnico e de crédito, teriam grandes chances de mudar o quadro rural do país, porém a agricultura familiar tão protegida e incentivada em grandes nações foi deixada de lado no Brasil (FAO, 1994 apud ALEIXO; CRUZ; LIMA, 2009).

Segundo Castelões (2002), as políticas públicas a favor da agricultura familiar surgiram no Brasil a partir da década de 90, devido a dois fatores: a crescente necessidade de intervenção estatal frente ao quadro crescente de exclusão social e o fortalecimento dos movimentos sociais rurais. O crescimento da miséria, da violência e da insegurança nas grandes cidades fez com que também crescesse o apoio da sociedade urbana às políticas de valorização do meio rural, a fim de conter a população no campo. Neste contexto em 1995 surgiu o Programa Nacional da Agricultura Familiar (PRONAF), graças à luta dos trabalhadores rurais por uma política pública específica e diferenciada para a agricultura familiar, o intuito da criação deste programa do governo federal foi atender de forma diferenciada os mini e pequenos produtores rurais que desenvolvem suas atividades mediante emprego direto de sua força de trabalho e de sua família. 
Rodrigo Lopes Antunes, Marcia Regina Gabardo Camara, Sidnei Pereira do Nascimento, Vanderlei José Sereia, João Amilcar Rodrigues Anhesini

Sabe-se que uma parcela significativa dos alimentos é produzida pelos pequenos produtores familiares e que os recursos do PRONAF são importantes para dar segurança ao pequeno produtor agrícola, pois favorece o oportuno e adequado custeio da produção e/ou investimento agrícola. Com a sexta maior população do país (conforme estimativa da população brasileira divulgado pelo IBGE Julho/2009), o estado do Paraná é o segundo em termos de contratos e montante de recursos do PRONAF (de acordo com os dados do SAF/MDA para o ano fiscal 2008), e também um grande produtor de grãos e alimentos no Brasil, com $45 \%$ produção agrícola originária, principalmente de propriedades familiares, e muitas dessas propriedades têm sido atendidas pelo PRONAF. Vale destacar ainda que o Paraná no ano de 2008 recebeu $14 \%$ de todo o montante destinado ao programa.

As perguntas de pesquisa são: qual é o impacto desta alocação de recurso do PRONAF sobre a economia local no estado do Paraná no período de 2000 2005? E também qual é a importância da produção e da oferta de alimentos das lavouras beneficiadas pelo PRONAF no estado? E por fim, qual é a importância deste programa como apoio ao desenvolvimento rural do Brasil? Para atingir os objetivos descritos acima, realizou-se uma análise dos principais indicadores agrícolas e sociais do estado para demonstrar a importância deste programa para o desenvolvimento rural do Paraná.

\section{ELEMENTOS TEÓRICOS PARA A ANÁlise DO CRÉDITO RURAL E DO PRONAF}

\section{A Informação Assimétrica no Crédito Rural no Brasil}

A informação assimétrica é um fator importante que norteia as decisões a respeito das políticas relativas ao crédito rural e as próprias decisões de crédito. Esta assimetria de informação cria condições desfavoráveis para a oferta de crédito onde o emprestador pode resolver não conceder empréstimo a todos os interessados, sem antes avaliar o risco de inadimplência. No lado da demanda, os tomadores de empréstimos podem não estarem tão informados quanto aos termos, cláusulas e condições do contrato de empréstimo (ALEEM 1993 apud ALVES et al., 2003). 
A teoria de informação assimétrica destaca que as partes interessadas têm níveis de informações diferenciados sobre o produto ou serviço em questão. No mercado de crédito agrícola este problema está relacionado a dois motivos: seleção adversa e risco moral. A seleção adversa ocorre porque os tomadores de empréstimos têm maior conhecimento sobre suas capacidades de saldarem suas dívidas do que os emprestadores, porém esta capacidade se diferencia de tomador a tomador de empréstimo, e as instituições financeiras cobram a mesma taxa de juros para todos os tomadores de crédito, gerando atração de projetos de maior risco (menor qualidade) e consequentemente maiores riscos de inadimplência. $\mathrm{O}$ aumento da inadimplência acaba pressionando a elevação das taxas de juros que atrai novamente mais tomadores inadimplentes e assim por diante (ALVES, et al., 2003).

O Risco Moral está relacionado às atitudes que podem ser tomadas por ambas às partes após terem assinado o contrato de empréstimo, como por exemplo, o tomador após pegar o empréstimo pode tomar atitudes que aumentem o risco do projeto e tais atitudes não são observáveis pelo emprestador, ou ainda nos períodos de inflação elevada não seria possível encontrar um indexador satisfatório.

Durante o período de 1960 até 1980 foi constatado um elevado grau de concentração de tomadores de empréstimos em grandes estabelecimentos, culturas intensivas em capital e nas regiões mais desenvolvidas, devido ao fato das preferências dos bancos em conceder empréstimos aos proprietários de terra que Ihes oferecessem um menor risco e menor custo operacional. Segundo Datey (1978 apud ALVES, et al., 2003), emprestar para a agricultura é mais caro que para qualquer outro ramo de negócio, pois se tem maior risco de perda (condições climáticas, preços de venda), e para os pequenos agricultores sem tecnologia é mais caro ainda, ou seja, os pequenos agricultores eram marginalizados do processo de crédito rural.

Surge então a necessidade de novas fontes de recursos, que precisavam considerar diferenças regionais, renda e patrimônio dos agricultores familiares, de forma a eliminar a assimetria de informação.

\section{Histórico da evolução do Crédito Rural no Brasil}

Até 1930 eram os comerciantes e exportadores que financiavam a grande maioria do crédito rural concedido, e recebiam como garantia ou forma de 
pagamento a penhora da produção ou a propriedade rural (FARIA, 2003 apud BACHA; DANELON; FILHO; 2006). As primeiras experiências de crédito rural no Brasil são datadas dos anos 30, onde o Banco do Brasil passou a atuar de forma mais direta no financiamento e compra de café (SPOLADOR, 2001; BARROS, 1979; MEYER et al., 1977 apud GIMENEZ; GIMENEZ; GOZER, 2008).

A política agrícola adotada em nosso país a partir de 1965 produziu um rápido crescimento da participação do crédito agrícola no total de investimentos da economia. (SAYAD, 1978; BARROS, 1979 apud GIMENEZ; GIMENEZ; GOZER, 2008).

O crédito agrícola teve um papel importante na constituição dos complexos agroindustriais no Brasil, em função de ser um elo entre o capital financeiro e a agricultura, possibilitando o progresso tecnológico, através da disseminação da chamada revolução verde (modelo de desenvolvimento baseado na intensiva utilização de sementes melhoradas, insumos industriais, mecanização, diminuição do custo de manejo, uso extensivo de tecnologia no plantio, na irrigação, na colheita e no Gerenciamento da Produção). No entanto, acentuou ainda mais exclusão social de uma parcela de agricultores familiares que não conseguiram acompanhar este desenvolvimento do campo, frente aos produtores com maiores fontes de recursos financeiros (SILVA, 2006).

A grande modernização da agricultura brasileira durante as décadas de 80 e 90, contou com um apoio do Estado oferecendo crédito barato, além de incentivos fiscais, comerciais, pesquisa e assistência técnica as camadas mais privilegiadas de produtores rurais (latifundiários). Devido à concessão de privilégios, a modernização da agricultura brasileira foi marcada principalmente pela exclusão social, formando uma classe social rural desempregada e/ou com baixíssimos poder de compra. Com resultado desta política agrícola chamada de "Modernização Conservadora", por volta de 28 milhões de pessoas deixaram o campo em busca de emprego e melhores condições de vida nas cidades (BERGAMASCO, 1996 apud ALEIXO; CRUZ; LIMA, 2009).

O Gráfico 1 apresenta a evolução do crédito rural entre 1969 e 1980. 
Gráfico 1 - Evolução do Crédito rural de 1969 até 1980 - Milhões de Reais constantes de 2007, deflacionados pelo IGP-DI centrado - fim do período (FGV).

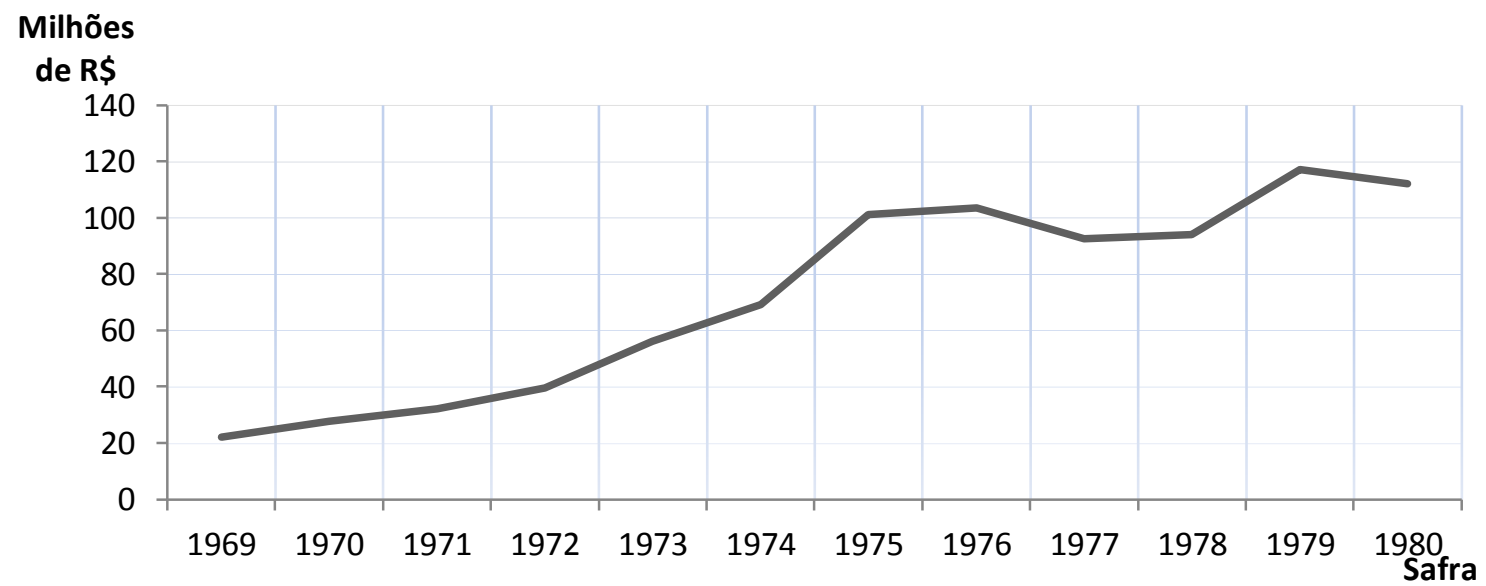

Fonte: Elaborado pelos Autores (2009), a partir de dados de dados Banco Central do Brasil - Anuário Estatístico do Crédito Rural (2007).

Com a crise econômica da década de 80 , o governo diminuiu de $20 \%$ para $12 \%$ a participação do crédito rural na soma da base monetária deste período. Por outro lado, a demanda por crédito rural estava crescendo rapidamente devido às condições favoráveis do mercado interno e internacional; mas em função da inflação crescente, os depósitos à vista minguaram aumentando a dependência de crédito rural das aplicações compulsórias dos bancos e da alocação de recursos de forma complementar por parte das autoridades monetárias. O governo neste período entendeu que umas das causas da inflação seria o subsídio dado ao crédito agrícola e as emissões monetárias utilizadas para financiar este setor, desta forma o governo decretou o fim da conta movimento do Banco do Brasil em 1986 (OLIVEIRA; MONTEZANO, 1982; SPOLADOR, 2001; SAYAD, 1982 apud GIMENEZ; GIMENEZ; GOZER, 2008).

Devido principalmente ao fim da conta movimento no Banco do Brasil em 1986, os recursos se tornaram ainda mais escassos e insuficientes, baseados apenas na fonte da caderneta de poupança. A ausência de subsídios agrícolas destacou a fragilidade do agronegócio no Brasil.

O Gráfico 2 permite verificar que na década de 1980, período em que a economia brasileira passou por momentos de inflação crescente e instabilidade econômica (devido ao segundo choque do petróleo em 1979), o governo diminuiu 
significativamente o volume de crédito concedido à agricultura. Diante deste contexto começaram a surgir modificações do SNCR (Sistema Nacional de Crédito Rural), no sentido de criar novas fontes de recursos, a principal fonte foi a Poupança Rural criada em 1986, que no ano de sua criação foi a principal supridora de recursos para os créditos concebidos ao setor agropecuário, superando os recursos advindos da exigibilidade dos bancos comerciais.

Gráfico 2 - Evolução do Crédito rural de 1980 até 1990 - Milhões de Reais constantes de 2007, deflacionados pelo IGP-DI centrado - fim do período (FGV).

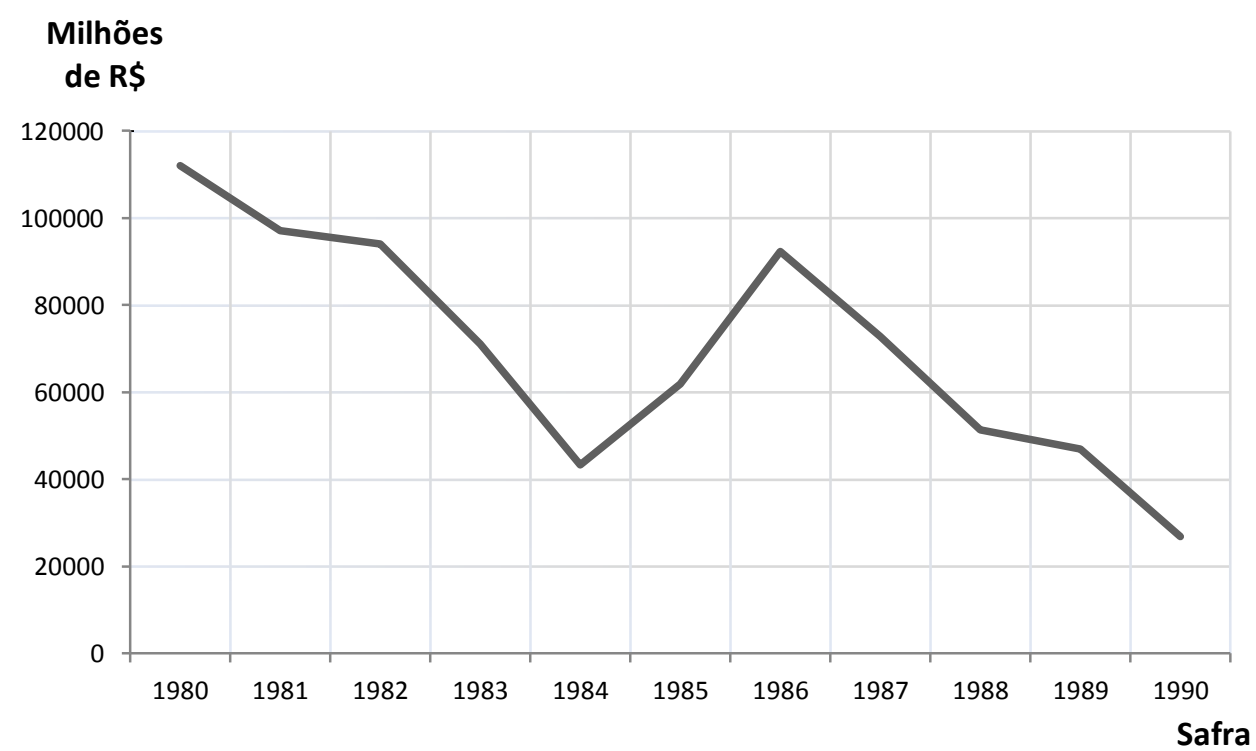

Fonte: Elaborado pelos Autores (2009), a partir de dados de dados Banco Central do Brasil - Anuário Estatístico do Crédito Rural (2007).

A partir dos anos 90 a agricultura brasileira que era anteriormente protegida, presenciou a diminuição das barreiras à importação e passou a ser totalmente exposta à concorrência internacional. Como resultado desta mudança, os agricultores familiares que não possuíam recursos e/ou assistência técnica adequada, não conseguiram acompanhar esta evolução e se tornaram menos competitivos em relação aos concorrentes internacionais (ROSA, 1999). Também como agravante, o governo federal passou a cobrar altas taxas de juros ao crédito rural e os recursos destinados à agricultura diminuíram.

Até o início destes anos não havia no Brasil qualquer política pública de âmbito federal voltada especialmente à agricultura familiar (CAZELLA; MATTEl; SHENEIDER, 2004). Neste cenário, surgiram os primeiros movimentos sociais do campo com o objetivo de buscar uma rápida reforma agrária e crédito rural a fim de 
resolver os problemas da grande massa de trabalhadores rurais oprimida pelos grandes agricultores e pecuaristas e pelo sistema concentrador de renda que prevalecia às exportações e a mecanização do campo. Com isto, gerava-se o subemprego dos trabalhadores, que poderiam estar produzindo produtos essenciais e gerando renda para as suas famílias, ou seja, diminuindo a exclusão e a marginalização social (ALEIXO; CRUZ; LIMA, 2009).

Em 1994 surgiu uma das mais importantes manifestações sociais de nossa história, o "Grito da Terra", que reuniu os representantes da CUT (Central Única dos Trabalhadores), MMC (Movimento das Mulheres Camponesas), MPA (Movimentos dos pequenos agricultores), MST (Movimento dos Sem terra), CONTAG (Confederação Nacional dos Trabalhadores da Agricultura), que foram de caravana até Brasília para reivindicar e negociar com o governo melhores linhas de crédito (FERNANDES, 2009). Em 1994, depois das pressões do "I Grito da Terra Brasil", foi conquistado o PROVAP (Programa de Valorização do Pequeno Agricultor) embrião do PRONAF, com esta conquista abriu-se uma fenda nas políticas públicas do crédito rural oficial que "reconheceu" a Agricultura Familiar. Em 1995 com o "Il Grito da Terra", conquistou - se o PRONAF, sendo implementado apenas o custeio; em 1996 com o "III Grito da Terra", conquistou-se a redução das taxas de juros para $6,5 \%$ a.a (ASFAGRO, 2009).

O PROVAP foi uma resposta do governo aos agricultores familiares que reivindicavam as regras vigentes na época que os consideravam como "miniprodutores", sendo submetidos às mesmas exigências que os grandes produtores para terem acesso ao crédito, ou seja, quase não possuíam as chances de receberem tais recursos. (SEAGRI, 2009).

Em 1995, o PROVAP foi totalmente reformulado na questão da concepção e na área de abrangência, com essas alterações deu origem ao PRONAF, cuja institucionalização ocorreu no decreto presidencial de $n^{0} 1.946$ de 28/07/96. Em 1996, os recursos destinados ao crédito foram implementados e em 1997 com a ampliação do programa (que passou a ser integrado a todo território nacional) foram implementados os recursos destinados a investimentos, infraestrutura e serviços municipais, capacitação e pesquisa (CAZELLA; MATTEI; SHENEIDER, 2009).

O Gráfico 3 apresenta uma comparação entre a evolução do crédito rural no Brasil durante os anos de 1990 e 2007 e o do PRONAF, desde sua institucionalização em 1996. Analisando o gráfico é possível verificar que a evolução 
do crédito do PRONAF apresenta uma linha de tendência bem semelhante ao total de recursos destinados aos agricultores no Brasil, muito embora em menor proporção que este, e também que a partir da aprovação do PROVAP (1994) e o PRONAF (1996) houve um crescimento contínuo do crédito rural total, apesar de somente a partir de 2004 os valores disponibilizados tenham alcançado as cifras de 1994.

Gráfico 3 - Comparação entre a evolução do crédito rural no Brasil durante os anos de 1990 até 2007 e o do PRONAF de 1996 até 2007 - Milhões de Reais constantes de 2007, deflacionados pelo IGP-DI centrado - fim do período (FGV).

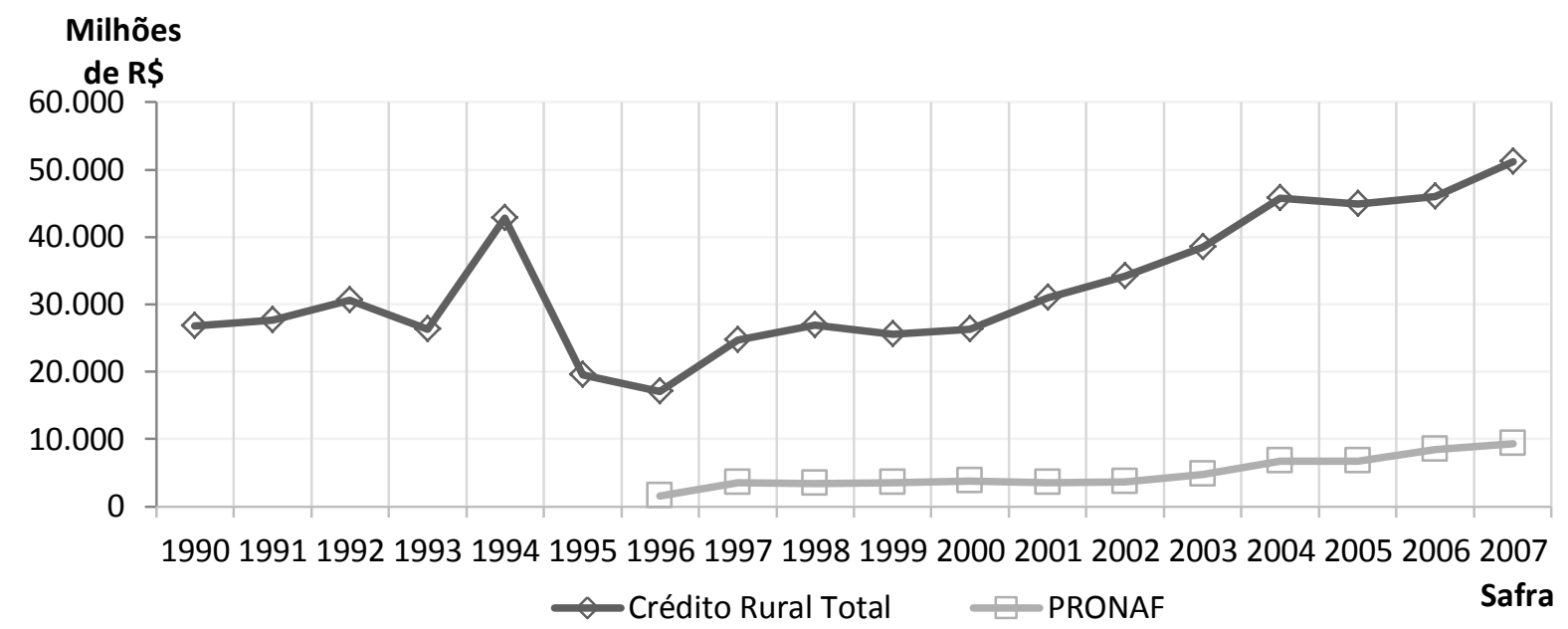

Fonte: Elaborado pelos Autores (2009), a partir de dados de dados Banco Central do Brasil - Anuário Estatístico do Crédito Rural (www.bcb.gov.br) (2007), SAF/MDA (2009) e SILVA (2006).

\section{A evolução do PRONAF no Brasil}

O programa vem modificando a estrutura da agricultura familiar, criando condições para que a pequena produção possa se expandir, melhorando seus produtos e processos de produção na busca pelo aumento do ganho das famílias agricultoras. A ação do Governo Federal também vem operando para eliminar as falhas que impedem que todo seu público alvo seja atingido (SAF, 2009).

A análise da evolução do PRONAF no Brasil será realizada em dois períodos de tempo: a fase inicial (1996 á 1999) e a fase mais recente dos recursos (1999 até 2008). Este corte temporal se justifica principalmente por dois motivos: primeiramente no período de 1996/1999 corresponde à fase inicial do programa onde somente em 1999 introduziu -se a diferenciação dos agricultores familiares beneficiários do PRONAF; o segundo motivo é que os dados disponíveis no site do 
PRONAF iniciam-se somente em 1999, e para esta análise foram utilizados os dados do Anuário Estatístico do Crédito Rural do Banco Central de 1995 a 1999, e conforme consta neste relatório, os dados podem estar subestimados, pois nem todos os recursos liberados na modalidade de investimento são contabilizados.

PRONAF: Fase Inicial

Os Gráfico 4 permite verificar os montantes de recursos liberados por regiões a partir de 1996, ano no qual o PRONAF foi instituído como programa (em 1995 quando criado, era apenas uma linha de custeio) e que a partir de 1997 houve um substancial aumento nas liberações de recursos e a política foi continuada nos anos posteriores.

Entretanto pelo menos nesta fase inicial o PRONAF não conseguiu atingir seu objetivo essencial que era facilitar o acesso ao crédito eliminando as concentrações de crédito aos agricultores de maior porte. Conforme o gráfico acima, o crédito se concentrou nas regiões onde os agricultores estavam mais integrados, em contrapartida as regiões de maior concentração de agricultores familiares (Nordeste) foram as que receberam menores recursos.

\section{Gráfico 4 - PRONAF Custeio e Investimento Regionalizado de 1996 a 1999 - valores constantes de 2007, deflacionados pelo IGP-DI centrado - fim do período (FGV).}

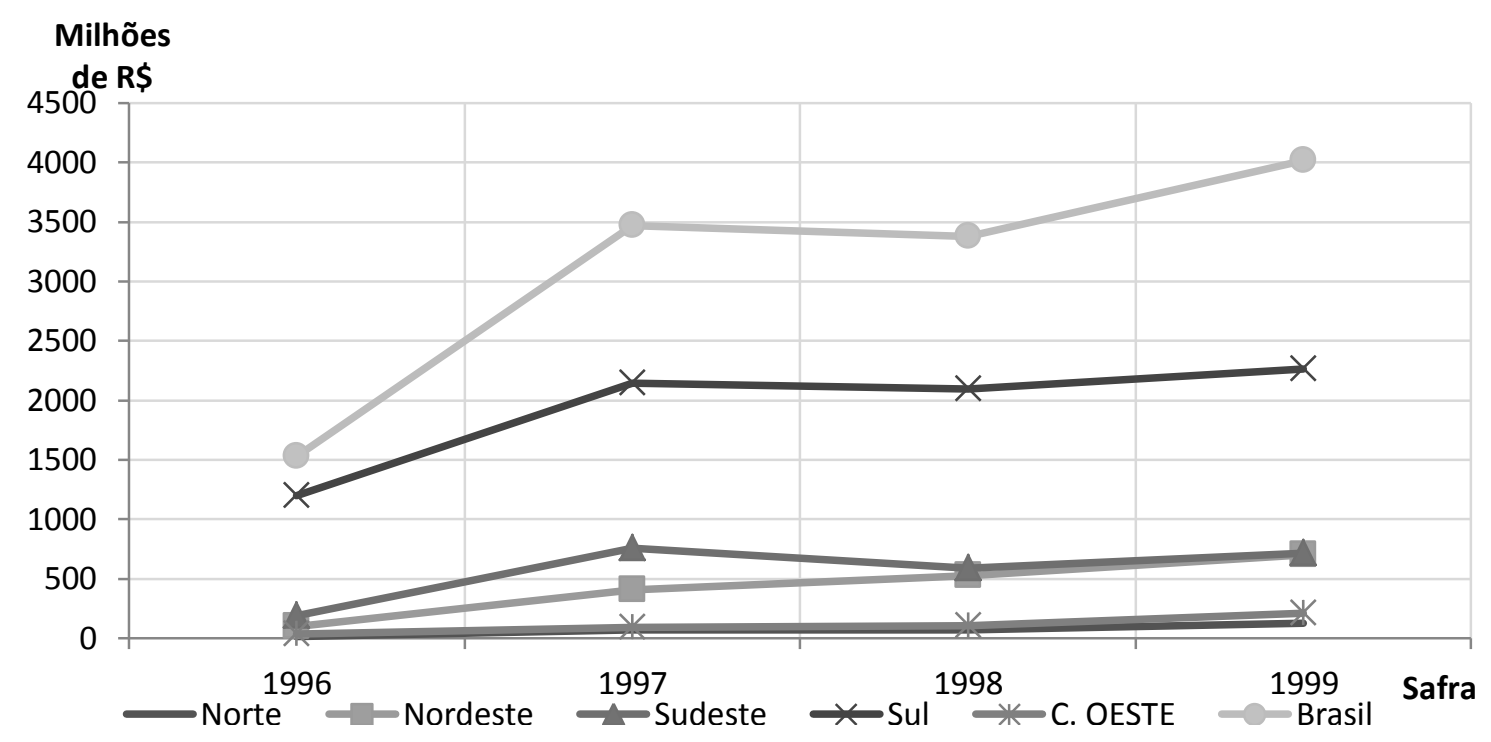

Fonte: Elaborado pelos Autores (2009) a partir de dados Banco Central do Brasil - Anuário Estatístico do Crédito Rural (vários anos) apud SILVA (2006).

A análise regional da Tabela 1 demonstra a importância da agricultura familiar para as regiões Norte e Sul, nas quais mais de $50 \%$ do valor bruto da produção destas regiões foi produzida nos estabelecimentos familiares. Na região 
Norte, os agricultores familiares representaram $85,4 \%$ dos estabelecimentos, ocupando $37,5 \%$ da área e produzindo $58,3 \%$ do valor bruto da produção desta região, recebendo $38,6 \%$ dos financiamentos. A região Sul foi a mais forte em termos de agricultura familiar comparada ao total de estabelecimentos, representando $90,5 \%$ de todos os estabelecimentos da região, ocupando $43,8 \%$ da área e produziu $57,1 \%$ do valor bruto da produção regional. Apesar desta região ser a segunda maior em termos de números de estabelecimentos, os agricultores familiares só ficaram com $43,3 \%$ dos financiamentos aplicados na região. (VIEIRA, et al., 2000).

O Centro-Oeste apresenta o menor percentual de agricultores familiares entre as regiões brasileiras, representando $66,8 \%$ dos estabelecimentos da região e ocupando apenas $12,6 \%$ da área regional e $12,7 \%$ dos financiamentos. A região Nordeste é a que apresenta maior número de estabelecimentos familiares (2.055.157 estabelecimentos) e fica com apenas $26,80 \%$ dos recursos de financiamento a atividade familiar (VIEIRA, et al., 2000).

Tabela 1 - Agricultura Familiar em número de estabelecimentos e área total Censo Agropecuário 1995/19996.

\begin{tabular}{|l|r|r|r|r|r|r|r|r|}
\hline \multicolumn{1}{|c}{ Regiões } & $\begin{array}{c}\text { No de Est. } \\
\text { Totais } \\
\text { Familiares }\end{array}$ & $\begin{array}{c}\text { \% } \\
\text { Est./ Total }\end{array}$ & $\begin{array}{c}\text { Área Total } \\
\text { (em ha) }\end{array}$ & $\begin{array}{c}\text { \% da } \\
\text { Área/Total }\end{array}$ & $\begin{array}{c}\text { Valor Bruto } \\
\text { da Produção }\end{array}$ & $\begin{array}{c}\text { \% Valor } \\
\text { Bruto/Total }\end{array}$ & $\begin{array}{c}\text { PRONAF PRONAF/ } \\
\text { (Mil R\$) }\end{array}$ & $\begin{array}{c}\text { Crédito Rural } \\
\text { Total }\end{array}$ \\
\hline Nordeste & 2.055 .157 & 88,30 & 34.043 .218 & 43,50 & 3.026 .897 & 43,00 & 133.973 & 28,80 \\
\hline Centro-Oeste & 162.062 & 66,80 & 13.691 .311 & 12,60 & 1.122 .696 & 16,30 & 94.058 & 12,70 \\
\hline Norte & 380.895 & 85,40 & 21.860 .961 & 37,60 & 1.352 .656 & 58,30 & 50.123 & 36,60 \\
\hline Sudeste & 633.620 & 75,30 & 18.744 .730 & 29,20 & 4.039 .483 & 24,40 & 143.812 & 12,60 \\
\hline Sul & 907.635 & 90,50 & 19.428 .230 & 43,90 & 8.575 .993 & 57,10 & 515.862 & 13,30 \\
\hline Brasil & 4.139 .369 & 85,20 & 107.768 .450 & 30,50 & 18.117 .725 & 37,90 & 937.828 & 25,30 \\
\hline
\end{tabular}

Fonte: Censo Agropecuário do IBGE 1995/1996 apud Viera (et al., 2000).

E por último a Região Sudeste que apresenta $29,2 \%$ da área e somente recebem $12,6 \%$ do crédito rural aplicado nesta região.

\section{PRONAF: A fase mais recente}

No que tange o valor total de liberações do PRONAF (todas as suas modalidades de recursos), pode se notar no Gráfico 5 que este montante apresentou um comportamento ascendente de 1999 a 2008. 
Gráfico 5 - Total de liberação do PRONAF no Brasil por modalidade de recursos de 1999 a 2008- valores constantes de 2007, deflacionados pelo IGPDl centrado - fim do período (FGV).

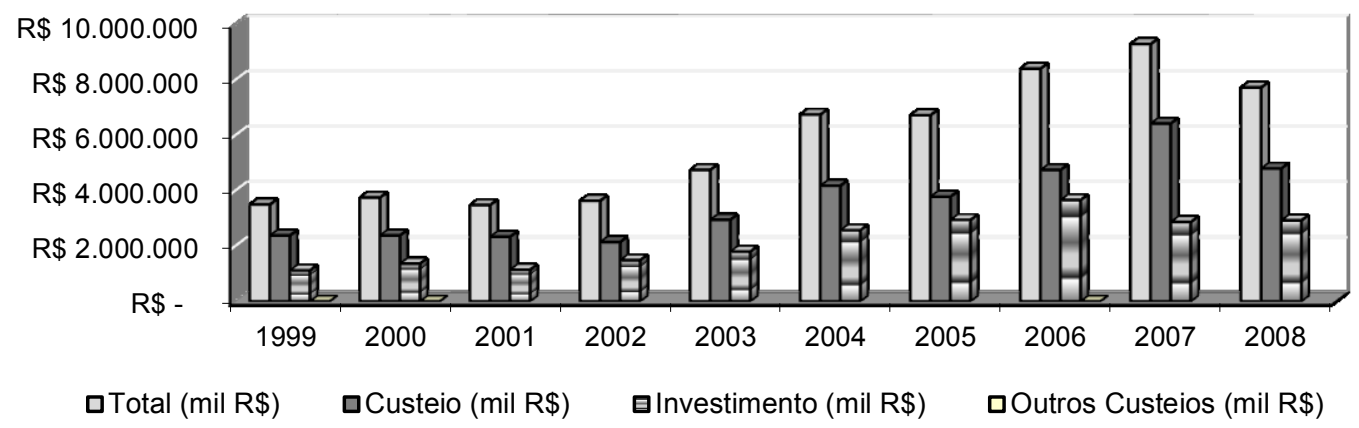

Fonte: Elaborado pelos Autores (2009) a partir de dados do site do PRONAF (www.pronaf.gov.br)

\section{Agricultura Familiar e a evolução do PRONAF no estado do Paraná}

A população do Paraná atualmente é de 10,6 milhões de habitantes (segundo estimativa divulgada pelo IBGE para julho de 2009), e já teve uma das maiores taxas de crescimento do país.

No ano de 2000, o Censo do IBGE revelou uma população ocupada de 4.055.739 para uma População Economicamente Ativa (PEA) de 4.651.832 pessoas. Destas, pouco mais de $20 \%$ estavam ocupadas diretamente na agropecuária, $22 \%$ na indústria, cerca de $17 \%$ no comércio e $39 \%$ em serviços. No entanto, muitos municípios paranaenses têm a maior parte da população ocupada na agropecuária e dependem basicamente dessa atividade. Dos 399 municípios do estado, 188 têm mais de $50 \%$ da PEA ocupada nesse setor, sendo a agricultura familiar responsável por muitos desses postos de trabalho (RELATÓRIO DO PRONAF, 2008).

No Censo Agropecuário de 2006 divulgado pelo IBGE foram identificados 302.907 estabelecimentos de agricultura familiar, o que representa $81,6 \%$ dos estabelecimentos totais do estado. Este grande número de agricultores familiares ocupa uma área de 4,2 milhões de hectares ou $27,80 \%$ da área ocupada. Ou seja, estes resultados mostram que à estrutura fundiária no estado ainda é muito concentrada em grandes produtores. A área média dos estabelecimentos familiares no estado segundo esta pesquisa é de 14 hectares, e a dos não familiares de 162 hectares.

Ainda com base no Censo Agropecuário de 2006, dos 4,2 milhões de hectares destinados à agricultura familiar, 31,4 \% são destinadas as pastagens, 
Rodrigo Lopes Antunes, Marcia Regina Gabardo Camara, Sidnei Pereira do Nascimento, Vanderlei José Sereia, João Amilcar Rodrigues Anhesini

$17,2 \%$ as áreas com matas, florestas ou sistemas agroflorestais, já a agricultura não familiar possui 30,25\% e 29,9\% respectivamente. Apesar da agricultura familiar possuir uma menor área em lavouras e pastagens no estado (1,9 e 1,3 milhões de hectares, respectivamente) ela é responsável pela oferta significativa dos alimentos. A agricultura familiar no estado é responsável por: $81 \%$ da produção de mandioca, $68 \%$ da produção de leite do estado (sendo 68\% leite de vaca e 58\% de cabra), 67\% do plantel de aves, 66 \% da produção de feijão (sendo $75 \%$ de feijão preto, $45 \%$ de feijão de cor e $44 \%$ de feijão fradinho), $62 \%$ do plantel de suínos; $57 \%$ da produção de café (valor formado por $56 \%$ do café arábica e $66 \%$ do tipo robusta), $44 \%$ da produção de milho em grão, 38\% da produção de arroz, 35\% do plantel de bovinos do estado. As culturas que possuem a menor participação da agricultura familiar no Paraná são a soja com $31 \%$ e o trigo com $23 \%$, sendo a soja um dos principais produtos da pauta de exportações brasileira.

Outro ponto que deve ser destacado no estado do Paraná em 2006 de acordo com o Censo Agropecuário é que $22 \%$ do total de estabelecimentos familiares ou 67,9 mil estabelecimentos, não contraíram financiamento agrícola pelos seguintes motivos: burocracia, medo de contrair empréstimos, inadimplência e problemas relacionados à assimetria de informação (falta de garantia pessoal, sendo avaliado pelo emprestadores como um risco de empréstimo e também pela falta de conhecimento por parte dos agricultores em como proceder à obtenção do financiamento).

Em relação ao montante de recursos do PRONAF no estado do Paraná, se observa um considerável crescimento desde 2000 tanto de volume de recursos como de contratos, conforme o Gráfico 6. No estado do Paraná, assim como ocorreu no Brasil nos anos de 2000 até os dias atuais, se nota a grande participação do montante de recursos com a finalidade de custeio no total de recursos liberados, e partir de 2006 neste estado também houve um aumento dos contratos com a finalidade de investimento 
Gráfico 6 - Contratos e liberações do PRONAF por modalidades de recursos no Paraná de 2000 a 2008-valores constantes de 2007, deflacionados pelo IGPDI centrado - fim do período (FGV).

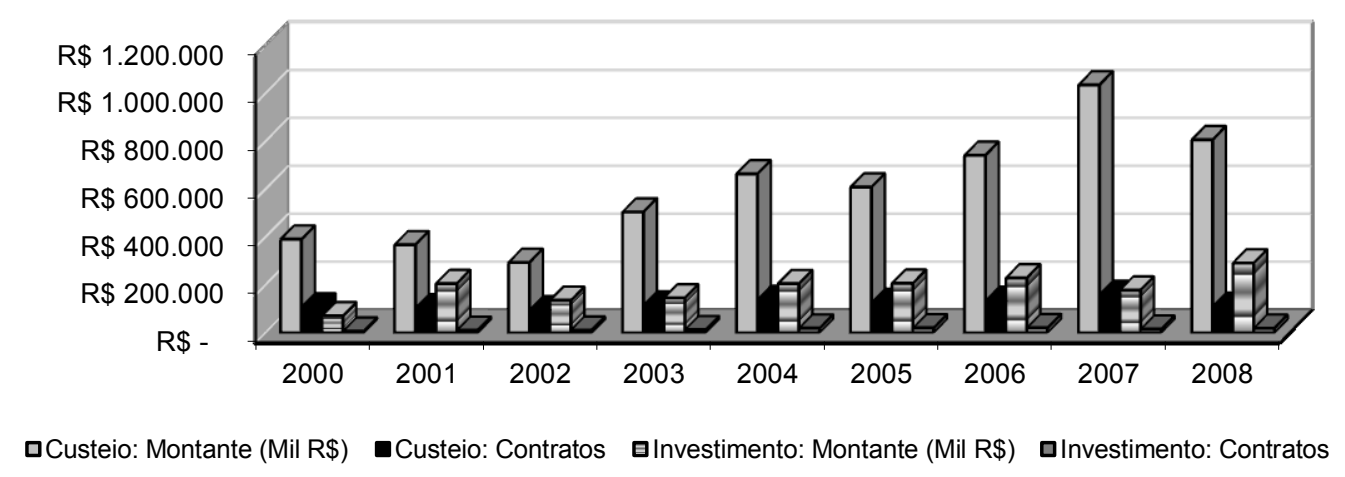

Fonte: Elaborado pelos Autores (2009) a partir de dados do SAF/MDA.

.As cidades de Medianeira e Cascavel possuem uma posição de destaque entre as maiores tomadores de empréstimo do PRONAF, conforme dados do SAF/MDA no período de 2000 a 2008.

\section{ANÁLISE DOS IMPACTOS DO PRONAF NAS ECONOMIAS LOCAIS NO ESTADO DO PARANÁ}

\section{Procedimentos Metodológicos}

Utilizou-se como base para a análise dos impactos do PRONAF, os procedimentos metodológicos desenvolvidos e utilizados por MATTEI, et al.(2007), cujo estudo não incluiu o estado do Paraná. Realizou-se modificação no número de amostras, período da análise e também algumas variáveis analisadas.

\section{Variáveis utilizadas}

A) Recursos do PRONAF: Os dados relativos ao montante de recursos no âmbito municipal foram fornecidos pela Secretaria da Agricultura Familiar do Ministério do Desenvolvimento Agrário (SAF/MDA).

B) Indicadores Econômicos: foi utilizado o PIB Agrícola municipal disponibilizado por meio do site IPEDATA em valores constantes de 2000. Desta forma, para estimar as regressões para o ano de 2005, os valores foram calculados para R\$ de 2005 utilizando o deflator implícito do PIB Nacional de 2005 (\% variação anual). 
Rodrigo Lopes Antunes, Marcia Regina Gabardo Camara, Sidnei Pereira do Nascimento, Vanderlei José Sereia, João Amilcar Rodrigues Anhesini

C) Indicadores de Produção: área plantada e quantidade produzida das lavouras temporárias e permanentes, disponibilizado por meio da PAM (Pesquisa Agrícola Municipal realizada pelo IBGE).

D) Indicadores de Emprego: dados referentes ao mercado formal de trabalho no setor agrícola obtido a partir da base estatística do Ministério do Trabalho e Emprego (RAIS e CAGED). Entretanto vale lembrar que os dados sobre o mercado de trabalho em áreas rurais são precários, além da falta de uma base atualizada sobre o comportamento do mesmo. (MATTEI, 2005).

E) Indicadores de Arrecadação tributária: utilizou-se os dados referentes à receita tributária municipal disponibilizado pelo site IPEADATA, a fim de analisar o comportamento da receita tributária anual arrecadada pelos municípios, o qual poderá indicar efeitos indiretos do programa em cada localidade (MATTEI, 2005).

\section{Período de Análise}

O período de análise envolve 2000 e 2005. A escolha do período a ser analisado foi uma decisão levando-se em consideração os seguintes fatos:

a) Somente a partir de 1999 introduziu-se a diferenciação dos agricultores familiares beneficiários pelo PRONAF;

b) Os dados a nível municipal, referentes ao montante de crédito do PRONAF somente estavam disponíveis pela Secretaria da Agricultura Familiar do Ministério do Desenvolvimento Agrário (SAF/MDA) a partir do ano de 2000;

c) Os dados a níveis municipais, referentes à arrecadação tributária e ao PIB Agropecuária infelizmente só estavam disponíveis pelo site IPEADATA até 2005 e 2006 respectivamente (caso estes dados estivessem disponíveis em um período mais recente, tornaria está análise ainda mais interessante).

Com o objetivo de analisar todas as variáveis citadas no item 3.1.1 na mesma base (ano) foi decidido à escolha do período de 2000 e 2005.

\section{Características da Amostra}

Os sessenta municípios não são uma amostra, mas um ranking classificado do maior para o menor tomador de crédito no conjunto do período, significando que todas as afirmações e considerações presentes no texto ficam restritas a este horizonte acima mencionado. Para se obter os sessenta municípios que mais receberam crédito nos últimos cinco anos, foram somados o montante real de 
crédito contratado em cada ano por todos os municípios. Para tanto, os valores foram deflacionados pelo índice de preços do IGP-DI (fim do período) de 2005, utilizando a seguinte fórmula: $\mathrm{Vd}=(\mathrm{VC} / \mathrm{lc}){ }^{*} \mathrm{Id}, \mathrm{Vd}=$ Valor corrigido pelo índice de preços, nesse caso, IGP-DI de 2005, Vc= Valor Corrente do respectivo ano, Ic= Índice Corrente do respectivo ano, Id= Índice do Ano Base (IGP-DI, 2005). O somatório do período foi ordenado do maior para o menor, chegando-se à listagem dos sessenta municípios com maior volume real de crédito.

\section{Modelo Econométrico}

Com o intuito de alcançar o objetivo geral deste estudo (analisar os impactos do PRONAF nas economias locais paranaenses), foi utilizado modelos de regressão linear simples para mensurar o efeito do volume de recursos que foi alocado pelo PRONAF sobre cada uma das variáveis selecionadas nas dimensões produtiva, social e tributária, em cada período (2000 e 2005, dados de corte ou cross section). Vale lembrar que as regressões foram feitas utilizando os valores de cada variável no seu respectivo ano, ou seja, serão estimados coeficientes em cada período e posteriormente estes coeficientes serão comparados a fim de analisar a evolução das relações entre as variáveis (MATTEl et al., 2007).

Nesse contexto segue a série de regressões utilizadas em cada período:

1) $L n$ PIBAGR $=\alpha+\beta_{1}$ Ln PRONAF $+u_{t}$

2) $\operatorname{Ln} A P L A N T=\alpha+\beta_{1} L n P R O N A F+u_{t}$

3) $\operatorname{Ln}$ QPRODU $=\alpha+\beta_{1}$ Ln PRONAF $+u_{t}$

4) $\operatorname{Ln}$ RTRIBU $=\alpha+\beta_{1}$ Ln PRONAF $+u_{t}$

5) $\operatorname{Ln}$ EMPREG $=\alpha+\beta_{1}$ Ln PRONAF $+u_{t}$

Onde:

Ln PIBAGR: Logaritmo natural do PIB agrícola;

Ln PRONAF: Logaritmo natural do montante de recursos do PRONAF;

Ln APLANT: Logaritmo natural da área plantada;

Ln QPRODU: Logaritmo natural da quantidade produzida;

Ln RTRIBU: Logaritmo natural da receita tributária;

Ln EMPREG: Logaritmo natural do emprego agrícola;

$\alpha$ : intercepto (constante);

$\beta_{1:}$ Coeficiente do regressor;

$u_{t:}$ termo estocástico (erro); 
Rodrigo Lopes Antunes, Marcia Regina Gabardo Camara, Sidnei Pereira do Nascimento, Vanderlei José Sereia, João Amilcar Rodrigues Anhesini

In: logaritmo natural de base "e" $(e=2,7 \mid 8)$.

Para uma melhor análise empírica dos dados, as equações foram estimadas com os valores transformados em logaritmos naturais, conforme a especificação do Modelo Log-linear (ou também conhecido como Log - Log ou log duplo) de equações econométricas, com base em Gujarati (2000), o coeficientes de inclinações estimados nestes modelos, $\beta$, mede a variação percentual em $Y$ para uma dada variação percentual em X.

\section{Resultados encontrados}

Antes de analisar os resultados encontrados, realizou-se uma análise mais crítica dos dados através de testes econométricos de heterocedasticidade (Teste de Breusch - Pagan-Godfrey (BPG) e White) e autocorrelação (Durbin Watson), a fim de verificar e validar a eficiência dos estimadores de MQO apresentados na Tabela 2 para o ano de 2000 e na Tabela 3 para o ano de 2005, estes resultados medem a relação dos recursos do PRONAF (variável independente) e a série de variáveis dependentes analisadas, com seus valores em seus respectivos anos.

Tabela 2 - Regressões para o ano de 2000

\begin{tabular}{l|c|c|c|c|c|}
\hline \multicolumn{1}{c}{$\begin{array}{c}\text { Variáveis } \\
\text { dependente }\end{array}$} & Coeficiente & Estatística t & Valor - & $\mathbf{R}^{2}$ & $\mathbf{R}^{2}$ ajus tado \\
\hline a) PIB agropecuário & 0,379 & 3,010 & 0,004 & 0,135 & 0,120 \\
\hline b) Área plantada & 0,418 & 2,946 & 0,005 & 0,130 & 0,115 \\
\hline c) Quantidade produzida & 0,341 & 2,612 & 0,011 & 0,105 & 0,090 \\
\hline d) Receita tributária & 1,052 & 2,734 & 0,008 & 0,114 & 0,099 \\
\hline e) Emprego & 0,419 & 1,552 & 0,126 & 0,040 & 0,023 \\
\hline * Nível de significância de 1\% (2,660) 5\% (2,00) e 20\% (1,289). \\
Fonte: Elaborado pelos Autores (2009).
\end{tabular}

Tabela 3 - Regressões para o ano de 2005

\begin{tabular}{|c|c|c|c|c|c|}
\hline $\begin{array}{c}\text { Variáveis } \\
\text { dependente }\end{array}$ & Coeficiente & Estatística t & Valor - P & $\mathbf{R}^{2}$ & $\mathbf{R}^{2}$ ajus tado \\
\hline a) PIB agropecuário & 0,729 & 5,006 & 0,000 & 0,302 & 0,290 \\
\hline b) Área plantada & 0,691 & 4,387 & 0,000 & 0,249 & 0,236 \\
\hline c) Quantidade produzida & 0,564 & 2,982 & 0,004 & 0,133 & 0,118 \\
\hline d) Receita tributária & 1,603 & 5,160 & 0,000 & 0,315 & 0,303 \\
\hline e) Emprego & 1,043 & 3,255 & 0,002 & 0,154 & 0,140 \\
\hline \multicolumn{6}{|c|}{ * Nível de significância de $1 \%(2,660) 5 \%(2,00)$ e $20 \%(1,289)$. } \\
\hline \multicolumn{6}{|c|}{ Fonte: Elaborado pelos Autores (2009). } \\
\hline \multicolumn{6}{|c|}{$\begin{array}{l}\text { Os resultados encontrados permitem verificar que ao nível de significância } \\
\text { ou seja, à medida que o valor de p-valor for menor ou igual a } 0,05 \text { ) }\end{array}$} \\
\hline
\end{tabular}


praticamente todas as variáveis analisadas nos dois períodos apresentaram-se estatisticamente significantes, a exceção foi a regressão (e) (emprego formal agrícola em 2000) que se apresentou não estatisticamente significante, muito embora esta tenha variado positivamente. Mas verifica-se que ao nível de significância de 12,6 \% esta variável é estatisticamente significante. Em síntese, os valores encontrados revelam que uma expansão dos recursos do PRONAF provoca efeitos positivos sobre os indicadores de produção (PIB agropecuário, área plantada, quantidade produzida), receita tributária e emprego formal agropecuário.

Assim como também encontrado por Bueno (2008) em alguns coeficientes da dimensão produtiva, as regressões para o ano de 2005 apresentaram valores de p (ou estatística $t$ ) mais estatisticamente significativos que em 2000, bem como maiores coeficientes $\left(\beta_{1}\right)$ nas variáveis analisadas. Analisando também o coeficiente de determinação ( $R^{2}$ e $R^{2}$ ajustado), embora este apresente um baixo valor, que pode ser justificado pela não incorporação de outras variáveis que explicam as variáveis dependentes analisadas, se verifica que para o ano de 2005 também ocorre um maior ajuste que em 2000, "mostrando que agora o PRONAF exerce um efeito maior do que antes em cada uma das variáveis analisadas" (MATTEI, et al., 2007, p.9), e assim comprovar a hipótese inicialmente que o PRONAF como uma política pública de apoio, também vem contribuindo positivamente no estado do Paraná sobre as dimensões sociais, produtivas e tributária.

\section{CONCLUSÃO}

O presente estudo analisou o impacto do PRONAF na economia local dos 60 municípios paranaenses que mais contrataram crédito no período analisado de 2000 e 2005. Foi também apresentado um breve histórico sobre a evolução do crédito rural no Brasil.

O processo de intervenção do estado na agricultura brasileira teve seu auge nos anos de 1960, com a criação do Sistema Nacional de Crédito Rural, em 1965, que tinha como objetivo modernizar a agricultura brasileira. A partir dos anos 1980, houve mudança no rumo da política agrícola, devido à crise da economia brasileira, diminuindo consideravelmente os recursos destinados à agricultura. Durante o início dos anos 90 surgiram os primeiros movimentos sociais do campo que pressionaram o governo com o objetivo de resolver os problemas da massa de trabalhadores oprimida (agricultores familiares), neste cenário em 1996 foi institucionalizado o 
PRONAF com o objetivo de fomentar a agricultura familiar, pois este segmento nunca teve uma política pública específica.

Este trabalho também analisou a evolução do programa no Brasil e no estado do Paraná, bem com a importância da agricultura familiar para este estado e do programa como apoio ao desenvolvimento rural do Brasil. Em relação à evolução desta linha de crédito no Brasil, destaca-se principalmente o expressivo aumento do número de contratos bem como o montante de crédito durante a $2^{\circ}$ fase pós 1999 , quando se introduziu a diferenciação dos agricultores familiares beneficiários do PRONAF. Já o desenvolvimento rural promovido por esta política pública no Brasil, destaca-se que a partir de sua criação, a camada de agricultores familiares antes completamente marginalizados, passou a ter um maior acesso ao crédito com uma política agrícola adequada a sua realidade e necessidade, criando condições para que a produção se expandisse, gerando renda, aumento da oferta de alimentos e integrando o agricultor familiar à cadeia do agronegócio de forma a não incentivar a sua saída do meio rural.

No tocante à análise dos recursos destinados ao Paraná e da importância da agricultura familiar para este estado, destacam-se dois pontos. Primeiramente foi observado que o crescimento do volume de recursos neste estado acompanhou o crescimento nacional. Um segundo ponto refere-se a grande importância da agricultura familiar para o estado, com base no censo agropecuário de 2006 divulgado pelo IBGE, apesar da agricultura familiar possuir uma menor área em lavouras e pastagens ela é responsável por cerca $45 \%$ da produção das principais culturas do estado e $65 \%$ do plantel de animais (suínos, aves e bovinos).

No tocante aos resultados encontrados no modelo econométrico, destacamse os seguintes pontos: Primeiramente, todas as variáveis analisadas se apresentaram estatisticamente significativa em ambos os períodos, revelando efeitos positivos do volume de recurso do PRONAF sobre tais variáveis. Na dimensão produtiva o $\beta_{1}$ indica que para um aumento de $1 \%$ dos recursos do PRONAF tende a causar um aumento de $0,379 \%$ no PIB Agrícola, $0,418 \%$ na área plantada e $0,341 \%$ na quantidade produzida para o ano de 2000, e no ano de 2005 0,729\%, 0,691\% e 0,564\% respectivamente. Na dimensão social esta relação está em 0,419\% para o ano de 2000 e 1,043\% em 2005, e já na dimensão tributária em 1,052\% (2000) e $1,603 \%(2005)$ 
E por fim, os volumes de recursos do PRONAF em 2005 para este ranking de cidades foi cerca de $\mathrm{R} \$ 214$ milhões a mais que em 2000, e os resultados encontrados nos valores de $\mathrm{p}$, estatística $t, \mathrm{R}^{2}$ e $\mathrm{R}^{2}$ ajustado, para o ano de 2005 se mostraram mais estatisticamente significativos do que 2000, bem como maiores coeficientes $\left(\beta_{1}\right)$ nas variáveis analisadas, revelando assim que o aumento dos recursos do PRONAF gera efeitos positivos nas dimensões estudadas.

Assim, conforme verificado neste estudo e também em outras análises já realizadas por autores consagrados, o PRONAF após 13 anos de sua institucionalização como a primeira política pública nacional destinada especificamente ao segmento de agricultores familiares, continua cumprindo seu objetivo geral, que de acordo com manual operacional do PRONAF, é propiciar condições para aumentar a capacidade produtiva e a geração de emprego e renda, de forma a melhorar a qualidade de vida dos agricultores familiares, integrando à cadeia do agronegócio e proporcionar-lhe agregação de valor ao produto e à propriedade, com a sua profissionalização e com a modernização do seu sistema produtivo.

Nesse sentido, conforme destaca Bueno (2008), o PRONAF tornou-se um instrumento fundamental para o debate do desenvolvimento rural, pois seu significado para a reprodução social no segmento de agricultores familiares é imprescindível, ressalta-se a necessidade de sua continuidade e, na medida do possível, a ampliação de suas ações.

\section{REFERÊNCIAS}

ALEIXO, C.E, CRUZ, C, E, LIMA, P.V. Importância do PRONAF na infra-estrutura, produção agropecuária e geração de renda nos assentamento do Nordeste. In: $X L V$ SOBER, 2007, Londrina. Anais da SOBER, 2007.

ALVES, A. et al. Assimetria de Informação e o Crédito Rural Brasileiro. 2003. 90 f. Dissertação. Centro de ciências empresariais da UNIPAR, Toledo, 2003.

ASFAGRO. História do crédito na agricultura familiar. Disponível em: $<$ http://www.asfagro.org.br/sitet/trabalhos_tecnicos/agricultura_familiar/historia_do_C r\%E9dito_na.pdf>. Acesso em: 04 maio 2009.

BACEN. Banco Central do Brasil. Disponível em: <http://www.bacen.gov.br>. Acesso em 10 junho 2009.

Anuário Estatístico do crédito rural de 2007. BACEN. Disponível em: < http://www.bcb.gov.br/?RELRURAL2007>. Acesso em: 15 abril 2009 
BACHA, C.J.C; DANELON, L; FILHO, E.D.B. Evolução da Taxa de Juros Real do Crédito Rural no Brasil - Período de 1983 a 2003. Passo Fundo, v. 14, n. 26, p.4669 maio 2005.

BELINK, W. Avaliação da Operacionalização do Programa PRONAF. Disponível em:<http://www.eco.unicamp.br/artigos/artigo175.htm>. Acesso em 24 maio 2009.

BUENO, L. R. Avaliação Econômica do PRONAF no estado do Paraná.

Florianópolis, Santa Catarina, 2008. 98 f. Dissertação de Mestrado. Centro

Socioeconômico da Universidade Federal de Santa Catarina, 2008.I

CASTELÕES, L. Agricultura familiar ocupa maior parte da área rural brasileira. Revista eletrônica de jornalismo científico. 10 outubro 2002.

CAZELLA, A, A.; MATTEI, L.; SCHNEIDER, S. Histórico, caracterização e dinâmica recente do PRONAF. Porto Alegre, Rio Grande do Sul, 2004.

CENSO Agropecuário 2006 do IBGE. Rio de Janeiro, p. 1-267. 2006. ISSN 01036157.

FERNANDES, S.A. Gênero e Políticas de crédito para mulheres rurais em Santa Catarina. 2006. Florianópolis. Dissertação apresentada a Universidade Federal de Santa Catarina, 2006.

FREITAS, J.C. A política Agrícola do Regime Militar de 1964: Aspectos Jurídicos, Financeiros e Socioeconômicos. Fortaleza, Ceará, 2008. 105f. Dissertação (Mestrado em Direito Constitucional). Centro de Ciências Jurídicas da Universidade de Fortaleza.

FINANCIAMENTO Rural. Disponível em:

<http://www.planetaorganico.com.br/comofin.htm>. Acesso em: 10 maio 2008.

GIMENEZ, R.M.T; GIMENEZ, F.P; GOZER, C. Evolução do Crédito rural no Brasil e o papel das cooperativas agropecuárias no financiamento dos produtores rurais. In:

XLVVI Congresso da Sociedade Brasileira de Economia, Sociologia e Administração Rural, 2008, Umuarama Anais da SOBER, 2008.

GUJARATI, D.N. Econometria Básica. São Paulo: Makron Books, 2000.

GUJARATI, D.N. Econometria Básica. Rio de Janeiro: Elsevier, 2006.

IPEADATA. Instituto de Pesquisa Econômica Aplicada. Disponível em: <http://www.ipeadata.gov.br>. Acesso em 31 Agosto 2008.

MATTEI, L. Impacto do PRONAF: análise de indicadores. Brasília: MDA. 2005.

MATTEI, L. et al. Uma análise dos impactos do PRONAF sobre as economias locais nas regiões Nordeste, Sudeste e Norte do Brasil. In: Congresso Brasileiro de Economia e Sociologia Rural, 2007, Londrina. Anais da SOBER, 2007.

MCR. Manual do Crédito Rural 2008. Disponível em:

<http://www.mda.gov.br/saf/arquivos /070611 7993.doc >. Acesso em 12 Junho 2009.

MDA. Ministério do Desenvolvimento Agrário. Disponível em:

<http://www.mda.gov.br>. Acesso em 04 março 2009.

MTE. Ministério do Trabalho e Emprego. Disponível em:

<http://sgt.caged.gov.br/index.asp>. Acesso em: 22 agosto 2009. 
OLIVEIRA,R. A. O Financiamento do PRONAF e os indicadores Agrícolas das Lavouras de Subsistência do estado do Ceará. Fortaleza, Ceará, 2008. Dissertação de Mestrado apresentada à Universidade Federal do Ceará.

PAM. Pesquisa Agrícola Municipal. Disponível em: <http://www.sidra.ibge.gov.br>. Acesso em: 22 agosto 2009.

PLANETA ORGÂNICO. Disponível em: <http://www.planetaorganico.com.br/>. Acesso em: 09 março 2009.

PLANO Safra 2008/2009. Disponível em:

<http://www.mda.gov.br/saf/arquivos/0834517738.pdf>. Acesso em: 03 março 2009.

RELATÓRIO do PRONAF 2008: Resultados da Etapa Paraná. Disponível em:

<http://www.mda.gov.br/saf /arquivos/0834315314.pdf >. Acesso em: 15 junho 2009.

SAF. Secretaria da agricultura familiar. Disponível em:

<http://www.mda.gov.br/saf/index.php?sccid=390. Acesso em: 20 abril 2009.

SEAGRI. Censo Agropecuário pode mostrar uma desaceleração do êxodo rural no sudoeste do Paraná. Disponível em:

$<$ http://www.seagriba.gov.br:80/noticias.asp?prt=true\&qact=view\&notid=9790>. Acesso em: 29 maio 2009.

SILVA, F.F. Distribuição de Crédito para a Agricultura: Um estudo do PRONAF a partir de um Indicador de Desenvolvimento Rural. 2006. 250 f. Dissertação (Mestrado em Economia) Instituto de Economia da Universidade Federal de Uberlândia, Minas Gerais, 2006.

SILVA FILHO, J. B. Programa Nacional de Fortalecimento da Agricultura Familiar PRONAF. Disponível em: <http://www.ceplac.gov.br/radar/Artigos/artigo26.htm>. Acesso em: 11 abril 2009.

ROSA, C. A agricultura familiar e o desenvolvimento local sustentável. In: O Seminário "Agricultura Familiar: Desafios para a Sustentabilidade", 1999. Anais do INCRA. Aracaju.

VIEIRA, P. et al. O novo Retrato da Agricultura Familiar: O Brasil redescoberto. Brasília: Projeto de Cooperação Técnica INCRA/ FAO, 2000. 